\title{
Interactions between $\beta$-carotene and lutein during absorption and the potential role of Niemann-Pick C1-like 1 transport protein
}

\author{
L. O'Sullivan, S. A. Aherne and N. M. O'Brien \\ Department of Food and Nutritional Science, University College Cork, Cork, Republic of Ireland
}

Recently, it has been suggested that, along with that of cholesterol, carotenoid absorption is a facilitated process ${ }^{(1)}$. The objective of the present study was to examine interactions that occur between $\beta$-carotene (BC) and lutein (LUT) during absorption and to examine the effect of ezetimibe (EZ) on carotenoid transport using the Caco-2 intestinal model system. EZ is a potent inhibitor of cholesterol absorption and is thought to interfere with the Niemann-Pick C1-like 1 (NPC1L1) transport protein on the apical membrane of enterocytes ${ }^{(2)}$. Caco- 2 cells were adjusted to a density of $5 \times 10^{4}$ cells $/ \mathrm{cm}^{2}$ on trans-well plates $(0.4 \mu \mathrm{m}$ pore size membrane $)$ and grown for $21-25 \mathrm{~d}$ until an intact differentiated monolayer was obtained. Carotenoid concentrations were determined spectrophotometrically and delivered to cell monolayers in a Tween 40 micelle as previously described ${ }^{(3)}$. Total transport (carotenoids recovered from cells and basolateral media) was examined for $1 \mu \mathrm{M}-\mathrm{BC}$ alone (control), a carotenoid mix ( $1 \mu \mathrm{M}-\mathrm{BC}$ and $0.25 \mu \mathrm{M}-\mathrm{LUT})$ and $1 \mu \mathrm{M}-\mathrm{BC}$ with increasing concentrations of EZ. Media were supplemented with chylomicron-stimulating compounds and incubated for $16 \mathrm{~h}$. BC was extracted from cell and basolateral media samples and was quantified by HPLC as previously described ${ }^{(3)}$.

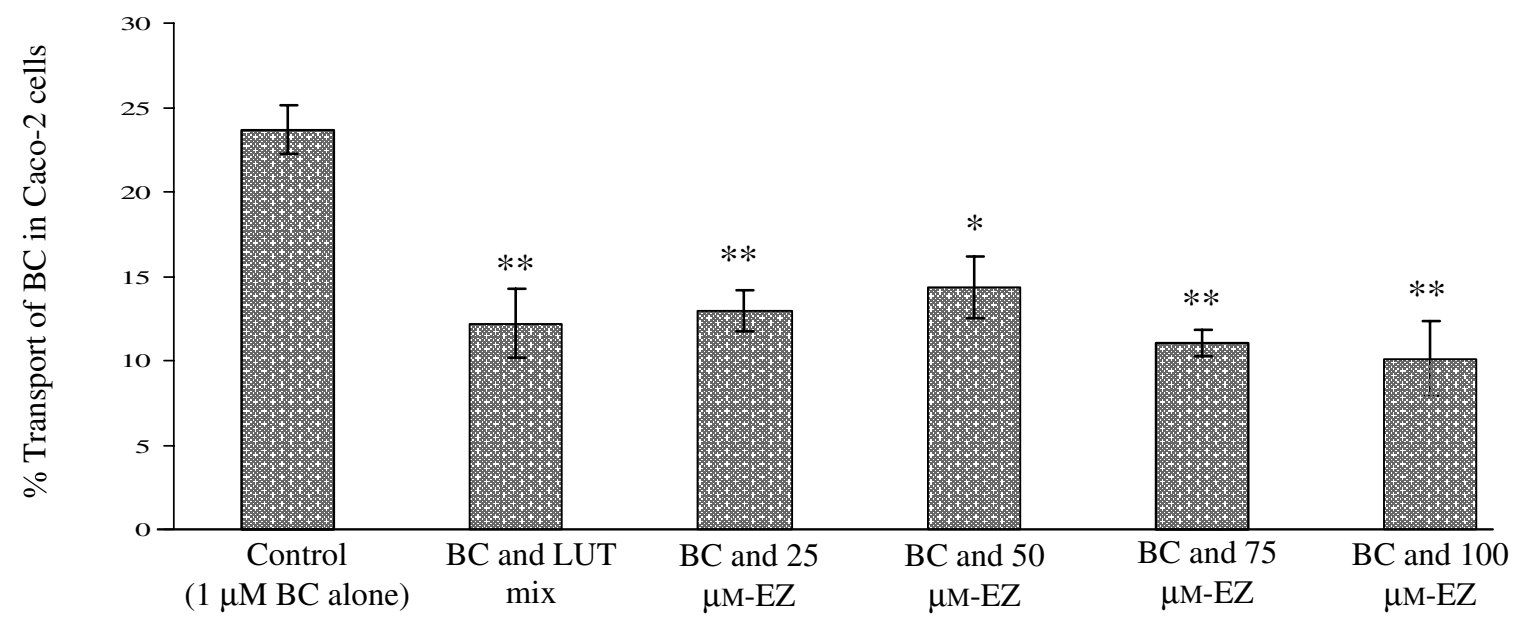

Fig. 1. Percentage BC transport in Caco-2 cells treated with BC, carotenoid mix or BC with increasing concentrations of EZ. Values are means with their standard errors represented by vertical bars. Values were significantly different from those for the control (Dunnet's test): $* P<0.05, * * P<0.01$.

$\mathrm{BC}$ transport from the mixed sample was significantly lower when compared with the control sample containing BC alone. These data clearly illustrate that BC and LUT interact during absorption in intestinal cells. This finding is in line with the results of a human study that has reported that LUT negatively affects BC absorption ${ }^{(4)}$. EZ at all concentrations significantly impaired BC transport. These data imply the possible involvement of a transporter protein such as NPC1L1 in BC transport. Data also suggest that BC and LUT may share a common transporter. The study adds to the growing body of evidence that absorption of carotenoids is a facilitated process and that carotenoids interact at the cellular level for absorption.

This research was funded by Science Foundation Ireland.

1. During A, Dawson H \& Harrison E (2005) J Nutr 135, 2305-2312.

2. Garcia-Calvo M, Lisnock J, Bull H et al. (2005) Proc Natl Acad Sci USA 102, 8132-8137.

3. O'Sullivan L, Ryan L \& O'Brien N (2007) Br J Nutr 98, 38-44.

4. van den Berg H \& van Vliet T (1998) Am J Clin Nutr 68, 82-89. 